\title{
Multisystem Inflammatory Syndrome Associated with SARS-CoV-2 Infection in an Adult: A Case Report from the Maldives
}

\author{
Ahmed Miqdhaadh ${ }^{1}$, Hisham Ahmed Imad ${ }^{2,3, *(D)}$, Aminath Fazeena ${ }^{1}$, Thundon Ngamprasertchai ${ }^{4}$, \\ Wang Nguitragool ${ }^{2,5}$, Emi E. Nakayama ${ }^{3}$ (D) and Tatsuo Shioda ${ }^{3}(\mathbb{D})$
}

check for updates

Citation: Miqdhaadh, A.; Imad, H.A.; Fazeena, A.; Ngamprasertchai, T.; Nguitragool, W.; Nakayama, E.E.; Shioda, T. Multisystem Inflammatory Syndrome Associated with SARS-CoV-2 Infection in an Adult: A Case Report from the Maldives. Trop. Med. Infect. Dis. 2021, 6, 187. https:// doi.org/10.3390/tropicalmed6040187

Academic Editor: John Frean

Received: 11 September 2021

Accepted: 18 October 2021

Published: 19 October 2021

Publisher's Note: MDPI stays neutral with regard to jurisdictional claims in published maps and institutional affiliations.

Copyright: (c) 2021 by the authors. Licensee MDPI, Basel, Switzerland. This article is an open access article distributed under the terms and conditions of the Creative Commons Attribution (CC BY) license (https:/ / creativecommons.org/licenses/by/ $4.0 /)$.
1 Department of Medicine, Indira Gandhi Memorial Hospital, Malé 20002, Maldives; migu313@hotmail.com (A.M.); aminathfazyna@gmail.com (A.F.)

2 Mahidol Vivax Research Unit, Faculty of Tropical Medicine, Mahidol University, Bangkok 10400, Thailand; wang.ngu@mahidol.edu

3 Department of Viral Infections, Research Institute for Microbial Diseases, Osaka University, Osaka 565-0871, Japan; emien@biken.osaka-u.ac.jp (E.E.N.); shioda@biken.osaka-u.ac.jp (T.S.)

4 Department of Clinical Tropical Medicine, Faculty of Tropical Medicine, Mahidol University, Bangkok 10400, Thailand; thundon.ngm@mahidol.ac.th

5 Department of Molecular Tropical Medicine and Genetics, Faculty of Tropical Medicine, Mahidol University, Bangkok 10400, Thailand

* Correspondence: hishamahmed.ima@mahidol.ac.th or imad@biken.osaka-u.ac.jp; Tel.: +66-631501402

Abstract: The multisystem inflammatory syndrome in adults (MIS-A) is a novel syndrome observed during COVID-19 outbreaks. This hyper-inflammatory syndrome is seen predominantly in children and adolescents. The case of an adult from the Maldives who had asymptomatic SARS-CoV-2 infection three weeks before presenting to the hospital with fever, rash, and shock is presented. De-identified clinical data were retrospectively collected to summarize the clinical progression and treatment during hospitalization and the six-month follow-up. SARS-CoV-2 infection was confirmed by RT-PCR. Other laboratory findings included anemia (hemoglobin: $9.8 \mathrm{~g} / \mathrm{dL}$ ), leukocytosis (leuko-

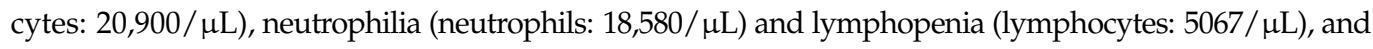
elevated inflammatory markers, including C-reactive protein $(34.8 \mathrm{mg} / \mathrm{dL})$ and ferritin $(2716.0 \mathrm{ng} / \mathrm{dL})$. The electrocardiogram had low-voltage complexes, and the echocardiogram showed hypokinesia, ventricular dysfunction, and a pericardial effusion suggestive of myocardial dysfunction compromising hemodynamics and causing circulatory shock. These findings fulfilled the diagnostic criteria of MIS-A. The case was managed in the intensive care unit and required non-invasive positive pressure ventilation, inotropes, and steroids. With the new surges of COVID-19 cases, more cases of MIS-A that require the management of organ failure and long-term follow-up to recovery are anticipated. Clinicians should therefore be vigilant in identifying cases of MIS-A during the pandemic.

Keywords: multisystem inflammatory syndrome; adults; clinical manifestations; COVID-19; Maldives

\section{Introduction}

The multisystem inflammatory syndrome in children (MIS-C) is a rare and distinct complication occurring predominantly in boys 6-10 years of age and is associated with the coronavirus disease-19 (COVID-19) outbreak [1,2]. This syndrome, when found in association with severe acute respiratory syndrome coronavirus 2 (SARS-CoV-2) infection, is characterized by a hyper-inflammatory state within the host. The clinical hallmarks of this syndrome include the elevation of inflammatory markers such as the C-reactive protein (CRP) and the acute-phase reactant ferritin, which is normally observed in the presence of organ dysfunction. This syndrome resembles Kawasaki disease, which, without treatment, can lead to complications with increased severity and morbidity resulting from coronary artery dilation and aneurysms [3]. 
During the first quarter of 2020, similar observations of a hyper-inflammatory syndrome associated with SARS-CoV-2 were reported in adolescents and adults [4-11]. The immunological host response to SARS-CoV-2 can lead to different recognizable immunological phenotypes, including the cytokine release syndrome (CRS) and the MIS-C or the multisystem inflammatory syndrome in adults (MIS-A). In CRS, a downregulated type $1 \mathrm{immune}$ response affects the pulmonary system, leading to pulmonary consolidation, edema, and eventually, acute respiratory distress syndrome [12]. In children and adults, the MIS causes the expression of immunologic mediators, such as cytokines, that have profound impacts on extra-pulmonary organs such as the gastrointestinal tract, the heart, the skin, and the brain. The incidence of MIS-C in children and adolescents was previously reported to be 5.1 persons per 1,000,000 person-months, whereas the frequency of MIS-A has not been reported [13].

At the time when the early cases were reported, what triggered the overt expression of cytokines by the host cells that would cause the physiological abnormalities exhibited in MIS from COVID-19 was largely unknown. It has been postulated that the immunological response is due to the presence of viral antigens or specific antibodies. In children, MIS-C develops after seroconversion, suggesting that the pathogenetic mechanism is a post-infection antibody-mediated response during convalescence [13]. The time to develop MIS-C after exposure to SARS-CoV-2 is reported to be within five weeks after infection [14]. The existing data regarding MIS-A suggest a similar convalescent response in adults [15-18]. Nevertheless, reports of a multisystem inflammatory syndrome after vaccination (MIS-V) in individuals who had received immunization after recovering from mild COVID-19, or perhaps non-neutralizing antibodies from other coronaviruses, suggest an alternative pathogenesis involving antibody enhancement that leads to the hyper-inflammatory syndrome [19-21].

The Maldives, located in the Indian Ocean, has a population of 551,735 people. At the time of writing, the crude fatality rate from COVID-19 was $0.3 \%, 15 \%$ of the population were confirmed to have COVID-19, and over $70 \%$ had received at least one dose of the vaccine against SARS-CoV-2. Several tropical infections are endemic to the islands, and the clinical findings of MIS-A may overlap with symptoms and signs of other tropical diseases. These include the clinical setting of plasma leakage in severe dengue, the vasculitis phenomenon in leptospirosis and rickettsiosis, and the aberrant host immune response to the superantigens in toxic shock syndrome and from hemophagocytic lymphohistiocytosis occurring in many infectious diseases. Despite these challenges, it is important to make the diagnosis and begin treatment promptly. Early recognition, with the aid of inflammatory biomarkers in the presence of organ dysfunction, will lead to early targeted therapy against the inflammatory response that causes organ damage.

The clinical progression and course of illness of an adult case of MIS-A from the Maldives is presented in this paper.

\section{Materials and Methods}

The case described here presented to Indira Gandhi Memorial Hospital in Malé, Maldives, in December 2020. De-identified clinical and laboratory data were reviewed using the patient medical chart, which included information during hospitalization and follow-up visits. SARS-CoV-2 infection was confirmed by RT-PCR (Liferiver, San Diego, CA, USA). Dengue diagnostics included SD Bioline Dengue Duo (Abbott Diagnostics, Yonginsi, Gyenoggi, Korea) and Panbio Dengue IgM/IgG ELISA (Abbott Diagnostics). Hemoculture was performed using an automated culture system (Biomeriuex, Durham, NC, USA). The previously described MIS-A case definition was used [22]. The criteria fulfilled were: severe illness requiring hospitalization in a person aged $\geq 21$ years; a positive test result for current or previous SARS-CoV-2 infection (nucleic acid, antigen, or antibody) during admission or in the previous 12 weeks; severe dysfunction of one or more extrapulmonary organ systems; laboratory evidence of severe inflammation; and absence of severe respiratory illness. Photographs were provided by the attending physician. 


\section{Case Report}

A 44-year-old man developed an acute undifferentiated febrile illness with a rash two days after completing 14-day home isolation, as shown in Figure S1. He remained asymptomatic after the confirmation of COVID-19 by RT-PCR. The onset of symptoms was described as mild, intermittent fever associated with chills. A maculopapular rash with lesions of varying sizes $(0.5-2 \mathrm{~mm})$ appeared on the abdomen simultaneously with the onset of fever. The rash was non-blanching, non-pruritic, and non-tender to palpation, and it desquamated rapidly into annular plaques with satellite lesions, as shown in Figure 1.

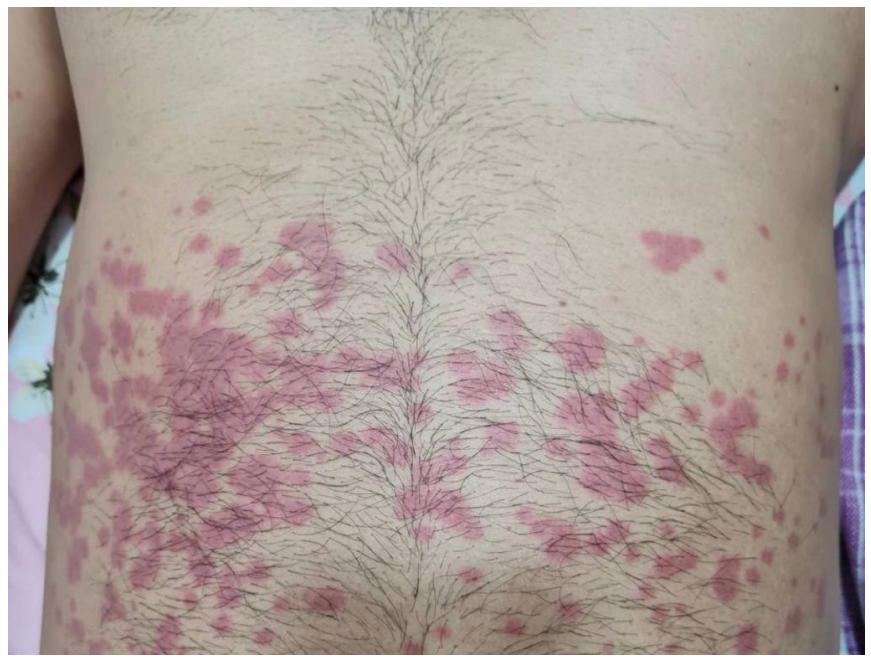

(a)

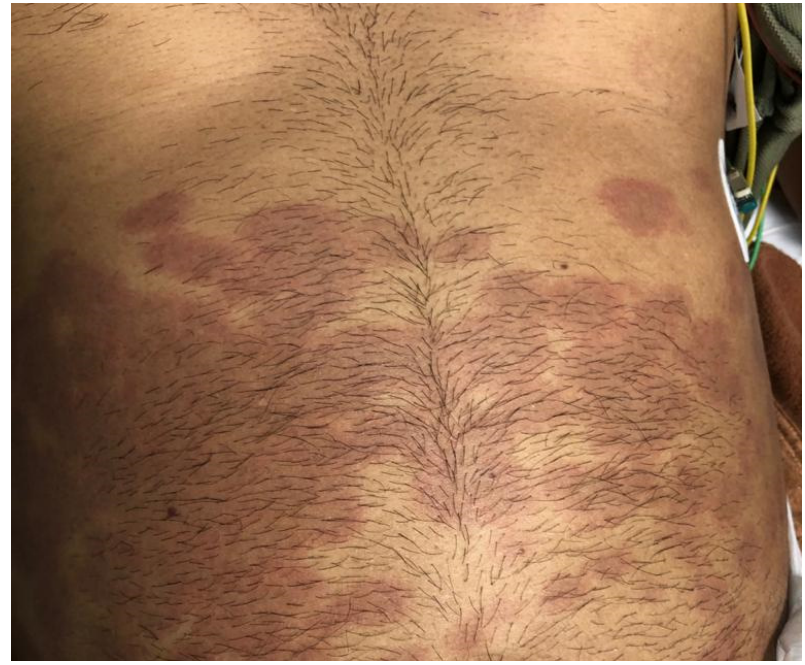

(b)

Figure 1. The evolution of a vasculitic rash. (a) Progression and clustering of the erupted maculopapular rash on the second day of illness; (b) desquamation with coalescence of an erythema multiforme-like lesion on the anterior surface of the abdominal wall upon presentation to the hospital (day six of illness).

The patient had presented to the emergency room with a complaint of extreme fatigue. There was an additional history of having several episodes of vomiting and diarrhea during the first few days of illness, but he denied experiencing abdominal pain. There was no history of headache, myalgia, arthralgia, bleeding, or any mucosal involvement. In addition, there was no history of any kind of respiratory symptoms, including coryza, sore throat, or cough. The chest X-ray at presentation is shown in Figure S2 and the ECG in Figure S3. Further history included a visit to a private clinic on the third day of illness, resulting in empiric antibiotic treatment (ciprofloxacin $1000 \mathrm{mg} /$ day).

On examination, the patient was conscious and lucid despite being in shock. The blood pressure was $84 / 52 \mathrm{mmHg}$, and the pulse was feeble and regular at 137 beats $/ \mathrm{min}$. The lower extremities were cool to the touch, with undetectable distal peripheral pulses and a prolonged capillary fill time. The oral temperature was $38.2^{\circ} \mathrm{C}$, and the respiratory rate was 20 breaths/min, with an oxygen saturation of $99-100 \%$ in room air. The tachycardia and distant heart sounds were audible with normal breath sounds through auscultation, and there was no neurological deficit. The routine laboratory results showed a left shift with leukocytosis and the predominance of neutrophils and anemia. The inflammatory markers and other biochemical results are shown in Table 1. 
Table 1. Serial hematological, biochemical profile and inflammatory markers.

\begin{tabular}{|c|c|c|c|c|c|c|c|c|c|}
\hline Day of Illness & 3 & 4 & 6 & 7 & 8 & 9 & 11 & 12 & 14 \\
\hline Hospitalization day & & & 1 & 2 & 3 & 4 & 6 & 7 & 9 \\
\hline Leukocyte/ $\mu \mathrm{L}$ & 17,000 & 15,200 & 20,900 & 21,200 & 23,400 & 27,100 & 22,490 & 16,833 & 10,800 \\
\hline Neutrophils/ $\mu \mathrm{L}$ & 13,815 & 13,710 & 18,580 & 17,935 & 20,779 & 23,469 & 5376 & 4764 & 9104 \\
\hline Lymphocytes & 1670 & 5321 & 5067 & 4822 & 5328 & 5542 & 258 & 270 & 691 \\
\hline Monocytes $/ \mu \mathrm{L}$ & 1879 & 188 & 250 & 193 & 300 & 403 & 4 & 0 & 421 \\
\hline Eosinophils $/ \mu \mathrm{L}$ & 17 & 0 & 0 & 0 & 5 & 31 & 0 & 0 & \\
\hline Basophils/ $\mu \mathrm{L}$ & 17 & 0 & 0 & 0 & 0 & 1 & 0 & 0 & \\
\hline Platelets $/ \mu \mathrm{L}$ & 157,000 & 161,000 & 207,000 & 257,000 & 324,000 & 413,000 & 537,000 & 549,000 & 499,000 \\
\hline Hemoglobin (g/dL) & 12.6 & 11.3 & 9.8 & 9.5 & 9.1 & 9.7 & 10.4 & 10.6 & 11.6 \\
\hline Hematocrit (\%) & 40.1 & 36.1 & 31.7 & 31.4 & 29.2 & 30.3 & 33.7 & 34.6 & 36.6 \\
\hline $\begin{array}{l}\text { Total bilirubin } \\
(\mathrm{mg} / \mathrm{dL})\end{array}$ & & 2.0 & 2.0 & 1.3 & 0.8 & 0.8 & 0.9 & 1.0 & 0.9 \\
\hline Total protein $(\mathrm{g} / \mathrm{dL})$ & & 6.4 & 6.4 & 5.3 & 5.3 & 5.6 & 5.1 & 4.9 & 5.1 \\
\hline $\begin{array}{c}\text { Alkaline } \\
\text { phosphatase (IU/L) }\end{array}$ & & 38 & 52 & 38 & 43 & 40 & 34 & 37 & 34 \\
\hline $\begin{array}{c}\text { Aspartate } \\
\text { aminotransferase } \\
(\mathrm{IU} / \mathrm{L})\end{array}$ & & 44 & 51 & 94 & 81 & 19 & 75 & 72 & 75 \\
\hline $\begin{array}{c}\text { Alanine } \\
\text { aminotransferase } \\
(\mathrm{IU} / \mathrm{L})\end{array}$ & & 24 & 31 & 58 & 75 & 94 & 92 & 118 & 20 \\
\hline Creatinine (mg/dL) & & 0.9 & 1.0 & 0.8 & 0.8 & 0.8 & 0.7 & 0.7 & 0.8 \\
\hline Urea $(\mathrm{mg} / \mathrm{dL})$ & & 16.9 & 28.4 & 37.8 & 37.8 & 38.5 & 32.1 & 39.5 & 15.0 \\
\hline $\mathrm{CRP}(\mathrm{mg} / \mathrm{dL})$ & & 22.6 & 34.8 & 31.7 & 15.7 & 8.8 & 2.6 & 1.7 & 0.9 \\
\hline Ferritin (ng/mL) & & & 2716 & 4235 & & 3499 & 2453 & 1840 & 1949 \\
\hline Fibrinogen (mg/dL) & & & 937 & & & & & & \\
\hline APTT (sec) & & & 49.5 & 51.9 & & 33.7 & & & \\
\hline $\mathrm{PT}(\mathrm{sec})$ & & & 16.5 & 17.2 & & 16.0 & & & \\
\hline INR & & & 1.5 & 1.6 & & 1.5 & & & \\
\hline LDH (IU/L) & & & 199 & & & 261 & & & \\
\hline D-dimer (ng/mL) & & & 1.3 & & & & & & \\
\hline Troponin I (ng/mL) & & & 1.0 & 0.6 & 0.8 & & & & \\
\hline CK (IU/L) & & & 138 & 101 & 83 & & & & \\
\hline CK-MB (IU/L) & & & 14 & 13 & 33 & & & & \\
\hline RT-PCR SARS-CoV-2 & & & Positive & & & & & & Negative \\
\hline Dengue NS1 & Negative & & Negative & & & & & & \\
\hline Dengue IgM & Positive & & Positive & & & & & & Negative \\
\hline Dengue IgG & Negative & & Negative & & & & & & Negative \\
\hline Hemo-culture & & & & & & & & & Negative \\
\hline Sputum culture & & & & & & & & & Negative \\
\hline Urine culture & & & & & & & & & Negative \\
\hline
\end{tabular}

CRP: C-reactive protein; APTT: activated partial thromboplastin time; PT: prothrombin time; INR: international normalized ratio; LDH: lactate dehydrogenase; D-dimer: domain dimer; CK: creatinine kinase; CK-MB: creatinine kinase myocardial band; NS1: nonstructural protein 1; IgM: immunoglobulin M; IgG: immunoglobulin G.

The patient received bolus fluid challenges and started receiving prophylactic broadspectrum antibiotics. Unfortunately, during vigorous resuscitation, the patient developed acute pulmonary edema; the intravenous fluids were consequently discontinued. Inotrope support was started with supplemental oxygen, and the patient was transferred to the intensive care unit (ICU) for further management, including non-invasive positive pressure ventilation. Echocardiography showed global left ventricular hypokinesia with a moderate left ventricular dysfunction. In addition to this, there was mitral and tricuspid valve regurgitation, with the dilation of all four chambers of the heart, pericardial effusion, and an ejection fraction (EF) less than $30 \%$. 
After a marked elevation of inflammatory markers in the presence of organ dysfunction, intravenous glucocorticosteroid (hydrocortisone $300 \mathrm{mg} /$ day) was started, given the clinical parameters meeting the MIS-A criteria. Over the next four to six hours, evident clinical improvement was observed. The patient became hemodynamically stable, and the positive pressure ventilator support was discontinued. Unexpectedly, on the third day of admission to the ICU, the patient developed new-onset symptomatic atrial fibrillation with a fast ventricular response, as shown in Figure S4. The abnormal heart rhythm was reverted back to sinus rhythm with antiarrhythmic and rate-controlling agents. A follow-up echocardiography performed prior to discharging the patient from the hospital demonstrated a resolution of the ventricular dysfunction, with an EF of 70\%.

However, residual dilated cardiomyopathy with mild pulmonary arterial hypertension and mild pericardial effusion remained. The patient was discharged on oral prednisolone (30 mg/day), ramipril (1.25 mg/day), metoprolol (100 mg/day), and spironolactone (12.5 mg/day). During the follow-up visits, the medications were tapered and then stopped six months later. The results of the routine investigations performed during the follow-up visits are shown in Table S1.

\section{Discussion}

The pathogenesis of MIS-A may be multifactorial, whereas the clinical trajectory reflects the host inflammatory responses that occur at different clinical phases of COVID-19 [23,24]. This hyper-inflammatory syndrome activates the endothelium, with ensuing thromboinflammation and microvascular dysfunction [25]. Beta coronaviruses show tropism to myocardial endothelial cells, and the cardiovascular system has frequently been affected in MIS-A [22]. The hyperinflammation stuns the heart, triggering myocarditis to cause biventricular failure and conduction defects [22,26]. The pathophysiology of myocarditis entails direct injury to myocytes, after which remodeling occurs, with persistent inflammation resulting in dilated cardiomyopathy [27].

Similarly, in the present patient, there was significant cardiovascular system involvement leading to structural abnormalities and a cardiovascular dysfunction consistent with previously described findings [22]. Part of the treatment included the early administration of an angiotensin-converting enzyme inhibitor, which, in pre-clinical trials, had been shown to reduce the remodeling from myocarditis [28]. Fortunately, the patient had a remarkable recovery and was completely asymptomatic with normal echocardiographic findings and biomarkers not suggestive of any further inflammation at six months. Cardiac magnetic resonance imaging is a valuable tool for detecting active myocardial inflammation, but it is not widely available. Therefore, the subsequent follow-up will be in six months, and if he remains asymptomatic, he will be followed up yearly.

Although the present patient had no past medical history and was otherwise considered a healthy adult, he was overweight (BMI $26.3 \mathrm{~kg} / \mathrm{m}^{2}$ ), and obesity has been associated with severe COVID-19 [29,30]. In addition, obesity also contributes to increased host meta-inflammation, and the adipocytes are known to express inflammatory cytokines such as interleukin 6, tumor necrosis factor-alpha, and acute phase reactants such as CRP [31]. As a result, there is sequestration of lymphocytes and other mononuclear cells in adipose tissue. Most of the cutaneous lesions were restricted to the truncal region with maximum adiposity, resembling an erythema multiforme-like rash [32]. A similar, annular rash has been previously described in a patient with MIS-A and heart failure [33]. Histopathological examinations of skin lesions in children have shown perivascular inflammation with the infiltration of lymphocytes [34,35].

Several tropical diseases are endemic to the Maldives, and clinicians use point-of-care test kits since many tropical diseases are indistinguishable upon presentation and can overlap with symptoms of MIS-A [36-38]. In the present case, the patient had a positive diagnosis of dengue IgM from ELISA, but this finding had to be carefully interpreted as false-positive dengue serology had been described in COVID-19 patients [39]. Crossreacting immunoglobulins with other flaviviruses have also been reported, but they could 
not be demonstrated in this case [40]. Despite the ELISA positive test results for dengue IgM in this case, the rapid test kit results for dengue IgM, IgG, and NS1 were all negative. Together with the clinical findings upon presentation, such as (a) the evidence of the extravasation of fluid into extra interstitial spaces (i.e., pericardial effusion) and (b) the absence of hemoconcentration or a narrowed pulse pressure characteristic of dengue hemorrhagic fever, the etiology of the illness is deemed unlikely to be dengue [41].

The patient denied any travel history and was mainly restricted to his home during the lockdowns. In addition to this, there was no contact with animals (rodents) or any exposure to floods that would indicate possible etiological agents of rickettsiosis and leptospirosis. Non-infectious differential diagnoses to be considered would be drug reaction, eosinophilia, and systemic symptoms (DRESS) [42]. However, the rash appeared before using antibiotics, and he did not meet any of the criteria for DRESS.

There are several limitations in this report. First, due to its retrospective nature, there was no access to any serum from the acute phase or during convalescence from leftover routine investigations to enable the isolation of the virus, demonstrate the expression of inflammatory cytokines, or detect antibodies against SARS-CoV-2 and exclude other likely viruses which are known to cause myocarditis. Furthermore, the cycle threshold $(\mathrm{Ct})$ value from the RT-PCR was only available for the initial confirmation of COVID-19, and it was not possible to trace the $\mathrm{Ct}$ value for the second positive test result performed during hospitalization. Lastly, no biopsy was performed to demonstrate the histological changes observed during MIS-A.

SARS-CoV-2 is a respiratory virus that primarily causes upper respiratory tract infections and pneumonia leading to lung fibrosis [43]. Growing evidence suggests the transmission route of the virus to be by aerosol spread, making it a potent contagion [44]. It is possible that SARS-CoV-2 infection can lead to a hyper-inflammatory state in adults, such as the MIS-A described in this report. In conclusion, a severe hyper-inflammatory syndrome with a febrile rash can occur in asymptomatic COVID-19 cases two weeks after a positive test.

Supplementary Materials: The following are available online at https:/ /www.mdpi.com/article/10 .3390/tropicalmed6040187/s1. Figure S1: Timeline showing the time from exposure to SARS-CoV-2 to developing multisystem inflammatory syndrome (MIS-A); Figure S2: Chest X-ray at the time of presentation to the hospital; Figure S3: Electrocardiogram taken in the emergency room; Figure S4: Clinical course from the time of admission to the intensive care unit to discharge from the hospital; Table S1: Follow-up routine laboratory results.

Author Contributions: Conceptualization, A.M., H.A.I., W.N., E.E.N. and T.S.; methodology, H.A.I., A.M., W.N., T.N., E.E.N. and T.S.; software, H.A.I.; validation, H.A.I., A.M., A.F., T.N., W.N., E.E.N. and T.S.; formal analysis, H.A.I., A.M., A.F., T.N., W.N., E.E.N. and T.S.; investigation, H.A.I., A.F. and A.M.; resources, A.M., W.N., E.E.N. and T.S.; data curation, H.A.I.; writing-original draft preparation, H.A.I., A.M., W.N., E.E.N. and T.S.; writing-review and editing, A.M., H.A.I., A.F., W.N., T.N., E.E.N. and T.S.; visualization, H.A.I.; supervision, A.M., W.N., E.E.N. and T.S.; project administration, H.A.I., A.F., A.M., W.N., E.E.N. and T.S.; funding acquisition, W.N., E.E.N. and T.S. All authors have read and agreed to the published version of the manuscript.

Funding: This study was funded by the Japan Agency for Medical Research and Development (AMED, grant numbers JP19m0108003 and 21wm0225010h0102). In addition, this work was supported by an International Postdoctoral Fellowship 2021 at Mahidol University through W.N. and H.A.I.

Institutional Review Board Statement: The study was conducted according to the guidelines of the Declaration of Helsinki and approved by the Institutional Review Board of Indira Gandhi Memorial Hospital, Malé, Republic of Maldives.

Informed Consent Statement: Informed consent was obtained from all subjects involved in the study.

Data Availability Statement: The data presented in this study are available on request from the corresponding author. The data are not publicly available to ensure the privacy of the study participant. 
Acknowledgments: The authors are sincerely grateful to the patient who volunteered to be part of this report in efforts to disseminate the knowledge of this rare and severe syndrome. The authors would also like to express their sincere appreciation to Zeena Fuad, Moosa Muaz, Moosa Hussen, Zaurath Abdulla, Shaneez Najmy, Mashee Abdulla, Anoosha Ahmed, Zaidhoo Jaleel, Fathimath Guraisha, Aishath Shifaly, Fathimath Reesha, Mahafooza Moosa, Miqdhaadh Shareef, Ali Shafeeq, Ali Latheef, Yoosuf Shan, and Ibrahim Saleem. A special thanks to all the staff at the Department of Medicine and to all the diligent nurses at the intensive care unit at Indira Gandhi Memorial Hospital.

Conflicts of Interest: The authors declare no conflict of interest.

\section{References}

1. Leon, M.P.D.; Redzepi, A.; McGrath, E.; Abdel-Haq, N.; Shawaqfeh, A.; Sethuraman, U.; Tilford, B.; Chopra, T.; Arora, H.; Ang, J.; et al. COVID-19-Associated Pediatric Multisystem Inflammatory Syndrome. J. Pediatr. Infect. Dis. Soc. 2020, 9, 407-408. [CrossRef] [PubMed]

2. Whittaker, E.; Bamford, A.; Kenny, J.; Kaforou, M.; Jones, C.E.; Shah, P.; Ramnarayan, P.; Fraisse, A.; Miller, O.; Davies, P.; et al. Clinical Characteristics of 58 Children with a Pediatric Inflammatory Multisystem Syndrome Temporally Associated With SARS-CoV-2. JAMA 2020, 324, 259-269. [CrossRef] [PubMed]

3. Tanaka, N.; Sekimoto, K.; Naoe, S. Kawasaki disease. Relationship with infantile periarteritis nodosa. Arch. Pathol. Lab. Med. 1976, 100, 81-86. [PubMed]

4. Moodley, P.; Tsitsi, J.M.L.; Reddy, D.L.; Debising, M.; Ickinger, C. A case of multisystem inflammatory syndrome in an African adolescent male: Case report. Pan. Afr. Med. J. 2021, 38, 174. [CrossRef]

5. Ahsan, T.; Rani, B. A Case of Multisystem Inflammatory Syndrome Post-COVID-19 Infection in an Adult. Cureus 2020, 12 , e11961.

6. Elouardi, Y.; Houssam, R.; Zarrouki, Y.; Ziadi, A.; Younous, S.; Samkaoui, A. COVID-19 associated Kawasaki-like multisystem inflammatory syndrome in an adult. Rev. Esp. Anestesiol. Reanim. 2020, in press. [CrossRef]

7. Pombo, F.; Seabra, C.; Soares, V.; Sá, A.J.; Ferreira, I.; Mendes, M. COVID-19-related Multisystem Inflammatory Syndrome in a Young Adult. Eur. J. Case Rep. Intern. Med. 2021, 8, 002520.

8. Chung, H.; Seo, H.; Park, S.; Kim, H.; Jung, J.; Chong, Y.P.; Kim, S.-H.; Lee, S.-O.; Choi, S.-H.; Kim, Y.S.; et al. The First Case of Multisystem Inflammatory Syndrome in Adult after COVID-19 in Korea. J. Korean Med. Sci. 2021, 36, e181. [CrossRef]

9. Yamada, Y.; Fujinami, K.; Eguchi, T.; Takefuji, H.; Mori, N. Multisystem Inflammatory Syndrome in Adults after Mild SARS-CoV-2 Infection, Japan. Emerg. Infect. Dis. 2021, 27, 1740-1742. [CrossRef]

10. Amato, M.K.; Hennessy, C.; Shah, K.; Mayer, J. Multisystem Inflammatory Syndrome in an Adult. J. Emerg. Med. 2021, 61, e1-e3. [CrossRef]

11. Brown, L.M.; Semler, M.W.; Hansen, M.; Person, A.K.; Kelly, S.G. Multisystem Inflammatory Syndrome in an Adult With COVID-19. Infect. Dis. Clin. Pract. 2021, 29, e174-e176. [CrossRef]

12. Moore, J.B.; June, C.H. Cytokine release syndrome in severe COVID-19. Science 2020, 368, 473-474. [CrossRef] [PubMed]

13. Payne, A.B.; Gilani, Z.; Godfred-Cato, S.; Belay, E.D.; Feldstein, L.R.; Patel, M.M.; Randolph, A.G.; Newhams, M.; Thomas, D.; Magleby, R.; et al. Incidence of Multisystem Inflammatory Syndrome in Children Among US Persons Infected With SARS-CoV-2. JAMA Netw. Open 2021, 4, e2116420. [CrossRef] [PubMed]

14. Gruber, C.N.; Patel, R.S.; Trachtman, R.; Lepow, L.; Amanat, F.; Krammer, F.; Wilson, K.M.; Onel, K.; Geanon, D.; Tuballes, K.; et al. Mapping Systemic Inflammation and Antibody Responses in Multisystem Inflammatory Syndrome in Children (MIS-C). Cell 2020, 183, 982-995. [CrossRef] [PubMed]

15. Julius, M.A.; Cantrell, D.; Sharif, S.; Zelnik, Y.D.; Rapoport, M.J. The First Fatal Post-COVID-19 Adult Patient with Multi-System Inflammatory Syndrome in Israel. Isr. Med. Assoc. J. 2021, 23, 212-213.

16. Altunisik, T.S.; Ersoy, Y.; Bayindir, Y.; Kilic, T.; Bayazit, V. Multisystem Inflammatory Syndrome in Adults (MIS-A) Associated with SARS-CoV-2 Infection in a Young Adult Case from Turkey. Medeni. Med. J. 2021, 36, 180-184.

17. van Heerden, J.; Nel, J.; Moodley, P.; Govender, P.; Hooijer, J.; Ickinger, C.; Lahri, S.; Louw, E.; Rabie, H.; Reddy, D.; et al. Multisystem Inflammatory Syndrome (MIS): A multicentre retrospective review of adults and adolescents in South Africa. Int. J. Infect. Dis. 2021, 111, 227-232. [CrossRef]

18. Cattaneo, P.; Volpe, A.; Cardellino, C.S.; Riccardi, N.; Bertoli, G.; Ursini, T.; Ustalli, A.; Lodi, G.; Daroui, I.; Angheben, A. Multisystem Inflammatory Syndrome in an Adult (MIS-A) Successfully Treated with Anakinra and Glucocorticoids. Microorganisms 2021, 9, 1393. [CrossRef]

19. Iyengar, K.P.; Nune, A.; Ish, P.; Botchu, R.; Shashidhara, M.K.; Jain, V.K. Multisystem inflammatory syndrome after SARS-CoV-2 vaccination (MIS-V), to interpret with caution. Postgrad. Med. J. 2021. [CrossRef]

20. Nune, A.; Iyengar, K.P.; Goddard, C.; Ahmed, A.E. Multisystem inflammatory syndrome in an adult following the SARS-CoV-2 vaccine (MIS-V). BMJ Case Rep. 2021, 14, e243888. [CrossRef]

21. Uwaydah, A.K.; Hassan, N.M.M.; Abu Ghoush, M.S.; Shahin, K.M.M. Adult multisystem inflammatory syndrome in a patient who recovered from COVID-19 postvaccination. BMJ Case Rep. 2021, 14, e242060. [CrossRef] [PubMed] 
22. Morris, S.B.; Schwartz, N.G.; Patel, P.; Abbo, L.; Beauchamps, L.; Balan, S.; Lee, E.J.; Paneth-Pollak, R.; Geevarughese, A.; Lash, M.K.; et al. Case Series of Multisystem Inflammatory Syndrome in Adults Associated with SARS-CoV-2 Infection-United Kingdom and United States-March-August 2020. U.S. Department of Health and Human Services/Center for Disease Control and Prevention. MMWR Morb. Mortal Wkly. Rep. 2020, 69, 1450-1456. [CrossRef] [PubMed]

23. Cordon-Cardo, C.; Pujadas, E.; Wajnberg, A.; Sebra, R.; Patel, G.; Firpo-Betancourt, A.; Fowkes, M.; Sordillo, E.; Painz-Mondolfi, A.; Gregory, J.; et al. COVID-19: Staging of a New Disease. Cancer Cell 2020, 38, 594-597. [CrossRef] [PubMed]

24. Ronit, A.; Jørgensen, S.E.; Roed, C.; Eriksson, R.; Iepsen, U.W.; Plovsing, R.R.; Storgaard, M.; Gustafsson, F.; Hansen, A.-B.E.; Mogensen, T.H. Host Genetics and Antiviral Immune Responses in Adult Patients With Multisystem Inflammatory Syndrome. Front. Immunol. 2021, 12, 718744. [CrossRef] [PubMed]

25. Boudhabhay, I.; Rabant, M.; Roumenina, L.T.; Coupry, L.M.; Poillerat, V.; Marchal, A.; Fremeaux-Bacchi, V.; El Karoul, K.; Monchi, M.; Pourcine, F.; et al. Case Report: Adult Post-COVID-19 Multisystem Inflammatory Syndrome and Thrombotic Microangiopathy. Front. Immunol. 2021, 12, 680567. [CrossRef] [PubMed]

26. McMurray, J.C.; May, J.W.; Cunningham, M.W.; Jones, O.Y. Multisystem Inflammatory Syndrome in Children (MIS-C), a Post-viral Myocarditis and Systemic Vasculitis-A Critical Review of Its Pathogenesis and Treatment. Front Pediatr. 2020, 8, 626182. [CrossRef]

27. Schultz, J.C.; Hilliard, A.A.; Cooper, L.T., Jr.; Rihal, C.S. Diagnosis and treatment of viral myocarditis. Mayo. Clin. Proc. 2009, 84, 1001-1009. [CrossRef]

28. Cohn, J.N.; Ferrari, R.; Sharpe, N. Cardiac remodeling-Concepts and clinical implications: A consensus paper from an international forum on cardiac remodeling. Behalf of an International Forum on Cardiac Remodeling. J. Am. Coll. Cardiol. 2000, 35, 569-582. [CrossRef]

29. Chou, J.; Platt, C.D.; Habiballah, S.; Nguyen, A.A.; Elkins, M.; Weeks, S.; Peters, Z.; Day-Lewis, M.; Novak, T.; Armant, M.; et al. Mechanisms underlying genetic susceptibility to multisystem inflammatory syndrome in children (MIS-C). J. Allergy Clin. Immunol. 2021, 148, 732-738. [CrossRef]

30. Kwok, S.; Adam, S.; Ho, J.H.; Iqbal, Z.; Turkington, P.; Razvi, S.; Le Roux, C.W.; Soran, H.; Syed, A.A. Obesity: A critical risk factor in the COVID-19 pandemic. Clin. Obes. 2020, 10, e12403. [CrossRef] [PubMed]

31. Huizinga, G.P.; Singer, B.H.; Singer, K. The Collision of Meta-Inflammation and SARS-CoV-2 Pandemic Infection. Endocrinology 2020, 161, bqaa154. [CrossRef] [PubMed]

32. Bennardo, L.; Nistico, S.P.; Dastoli, S.; Provenzano, E.; Napolitano, M.; Silvestri, M.; Passante, M.; Patruno, C. Erythema Multiforme and COVID-19: What Do We Know? Medicina 2021, 57, 828. [CrossRef] [PubMed]

33. Moghadam, P.; Blum, L.; Ahouach, B.; Radjou, A.; Lambert, C.; Scanvic, A.; Martres, P.; Decalf, V.; Begon, E.; Bachmeyer, C. Multisystem Inflammatory Syndrome With Particular Cutaneous Lesions Related to COVID-19 in a Young Adult. Am. J. Med. 2021, 134, e36-e37. [CrossRef] [PubMed]

34. So, N.A.; So, J.; Centkowski, S.; Rana, J.; Aleshin, M.; Kwong, B.Y.; Rieger, K.; Zaba, L.C.; Chiou, A.D. Histopathologic correlation of skin manifestations of multisystemic inflammatory syndrome in adults (MIS-A) associated with SARS-CoV-2 infection. JAAD Case Rep. 2021, 16, 108-109. [CrossRef]

35. Rongioletti, F.; Ferreli, C.; Sena, P.; Caputo, V.; Atzori, L. Clinicopathologic correlations of COVID-19-related cutaneous manifestations with special emphasis on histopathologic patterns. Clin. Dermatol. 2021, 39, 149-162. [CrossRef]

36. Imad, H.A.; Phadungsombat, J.; Nakayama, E.E.; Kludkleeb, S.; Matsee, W.; Ponam, T.; Suzuki, K.; Leaungwutiwong, P.; Piyaphanee, W.; Phumratanaprapin, W.; et al. Chikungunya Manifestations and Viremia in Patients Who Presented to the Fever Clinic at Bangkok Hospital for Tropical Diseases during the 2019 Outbreak in Thailand. Trop. Med. Infect. Dis. $2021,6,12$. [CrossRef]

37. Imad, H.A.; Tanyaratsrisakul, S.; Piyaphanee, W.; Wattanagoon, Y. Skin lesion from Maldives: Classic but forgotten. Travel Med. Infect. Dis. 2017, 17, 74-75. [CrossRef]

38. Hilmy, A.I.; Dey, R.K.; Imad, H.A.; Yoosuf, A.A.; Nazeem, A.; Latheef, A.A. Coronavirus disease 2019 and dengue: Two case reports. J. Med. Case Rep. 2021, 15, 171. [CrossRef]

39. Yan, G.; Lee, C.K.; Lam, L.T.M.; Yan, B.; Chua, Y.X.; Lim, A.Y.N.; Phang, K.F.; Kew, G.S.; Teng, H.; Ngai, C.H.; et al. Covert COVID-19 and false-positive dengue serology in Singapore. Lancet Infect. Dis. 2020, 20, 536. [CrossRef]

40. Hunsperger, E.A.; Yoksan, S.; Buchy, P.; Nguyen, V.C.; Sekaran, S.D.; Enria, D.A.; Vazquez, S.; Cartozian, E.; Pelegrino, J.L.; Artsob, H.; et al. Evaluation of commercially available diagnostic tests for the detection of dengue virus NS1 antigen and anti-dengue virus IgM antibody. PLoS Negl. Trop. Dis. 2014, 8, e3171. [CrossRef]

41. Imad, H.A.; Phumratanaprapin, W.; Phonrat, B.; Chotivanich, K.; Charunwatthana, P.; Muangnoicharoen, S.; Khusmith, S.; Tantawichien, T.; Phadungsombat, J.; Nakayama, E.E.; et al. Cytokine Expression in Dengue Fever and Dengue Hemorrhagic Fever Patients with Bleeding and Severe Hepatitis. Am. J. Trop. Med. Hyg. 2020, 102, 943-950. [CrossRef] [PubMed]

42. Sharifzadeh, S.; Mohammadpour, A.H.; Tavanaee, A.; Elyasi, S. Antibacterial antibiotic-induced drug reaction with eosinophilia and systemic symptoms (DRESS) syndrome: A literature review. Eur. J. Clin. Pharmacol. 2021, 77, 275-289. [CrossRef] [PubMed]

43. Scelfo, C.; Fontana, M.; Casalini, E.; Menzella, F.; Piro, R.; Zerbini, A.; Spaggiari, L.; Ghidorsi, L.; Ghidoni, G.; Facciolongo, N.C. A Dangerous Consequence of the Recent Pandemic: Early Lung Fibrosis Following COVID-19 Pneumonia-Case Reports. Ther. Clin. Risk Manag. 2020, 16, 1039-1046. [CrossRef]

44. Greenhalgh, T.; Jimenez, J.L.; Prather, K.A.; Tufekci, Z.; Fisman, D.; Schooley, R. Ten scientific reasons in support of airborne transmission of SARS-CoV-2. Lancet 2021, 397, 1603-1605. [CrossRef] 